Marcelo Pereira Lima'

'Universidade Federal da Bahia, Salvador, BA, Brasil

\title{
O "direito" de falar em pleitos: 0 gênero nos códigos jurídicos afonsinos
}

Resumo: Este artigo não é uma tentativa de estudar a vocalidade ou a oralidade em textos escritos e jurídicos assumidos por figuras femininas. Embora isso seja importante dentro dos limites metodológicos do que sugerem as documentações que analiso, o que tenho em mente é saber se, como e por que as diretrizes de gênero atuaram de maneiras transversais nos discursos produzidos pela legislação do governo de Afonso X (1252-1284), sobretudo no que toca a determinadas atividades, práticas ou ofícios jurídicos que estão direta ou indiretamente associados à credibilidade do falar ou do uso das palavras. A proposta aqui é testar as possibilidades da proposição de uma História Institucional de Gênero, combinando o campo da História Cultural do Direito Medieval e os Estudos de Gênero. Discutimos as interseccionalidades ou transversalidades constituídas entre relações de poder e processos de significação, isto é, a "d(en)ominação".

Palavras-chave: Gênero; Linguagem; Afonso X; História do Direito Medieval

\section{Introdução}

Gostaria de conversar um pouco com vocês sobre uma das últimas retomadas e revisões que tenho feito da minha pesquisa doutoral. Ela faz parte de um dos capítulos da tese que revisei neste ano para a publicação, provavelmente, em 2018 . Este artigo não é uma tentativa de estudar a vocalidade ou a oralidade em textos escritos e jurídicos. Pelo contrário, o que tenho em mente é saber se, como e por que as diretrizes de gênero atuaram de alguma forma no discurso jurídico produzido pela legislação do governo de Afonso $X$ (1252-1284), sobretudo no que toca a determinadas atividades, práticas ou ofícios jurídicos que estão direta ou indiretamente associados ao problema da credibilidade do falar ou do uso das palavras em pleitos. Parto do pressuposto de que o gênero é tanto uma categoria de análise, quanto um fenômeno a ser descrito, interpretado, compreendido, analisado e,

\section{(c) (7)}

Esta obra está sob licença Creative Commons. 
quando é possível fazê-lo, explicado do ponto de vista histórico e historiográfico. Mais do que uma mera noção e longe de ser um conceito fechado, considero importante encará-lo como uma categoria relativamente aberta, embora não acentuadamente escancarada e imprecisa.

Embora haja discordâncias sobre os contortos e alcances teóricos, metodológicos e epistemológicos sobre esse termo, vale explicitar três parâmetros importantes para este estudo (Joan SCOTT, 1995; Louise A. TILLY, 1994, p. 29-62; Eleni VARIKAS, 1994, p. 63-84; Lia Zanotta MACHADO, 1998; Claudia de Lima COSTA, 1994, p. 141-174). O primeiro valoriza a problematização crítica dos determinismos biológicos, discutindo como as naturalizações e essencializações "genderizadas" foram tradicionalmente constituídas, mantidas, legitimadas, alteradas e resistidas. O segundo presume a discussão sobre como as experiências discursivas ou os discursos experimentados (re)criaram o que se considera "homem", "mulher", "homens" e "mulheres", o "masculino" e o "feminino", as "masculinidades" e "feminilidades" ou, mesmo, outras possíveis configurações não binárias ou não dicotômicas ao longo do tempo. O terceiro parâmetro questiona as transversalidades, interseccionalidades e mobilidades que as diretrizes de gênero possuiriam com outros marcadores sociais, tais como, entre outros elementos, os aspectos etários, as condições econômico-materiais, as dinâmicas socioculturais, as relações de poder, o que é mais relevante aqui.'

Interessam-me as relações entre Direito e Gênero, entre instituições jurídicas e as diretrizes de gênero, o que significa dizer que o gênero possuiria diversos pesos, dimensões e orientações que podem interferir naquilo que seriam as estilizações "inventadas" ou construídas por uma cultura jurídica e um discurso monárquico claramente "genderizado". Vale lembrar que mantive as citações documentais em castelhano medieval em virtude das suas aproximações com o português, facilitando a identificação das marcas e propriedades textuais e, por fim, para que fosse útil aos interessados na análise do discurso histórico (Eni P. ORLANDI, 2000; 2001a; 2001b; 2003). O artigo possui duas preocupações dispostas de forma desigual: inicialmente, discorreremos sobre o que se está entendendo por História Institucional de Gênero, como um esforço de articular o campo dos Estudos de Gênero e a História Cultural do Direito Medieval Ibérico. Em seguida, mais extensamente, e de maneira mais documental, nos deteremos sobre como o "direito/privilégio" de falar em pleitos pode sofrer interferências de diversos marcadores sociais, incluindo as diretrizes de gênero, especialmente nos discursos jurídicos afonsinos de meados do século XIII.

\section{O "direito/privilégio" de falar em pleitos: para uma História Institucional de Gênero}

Essa pesquisa decorreu da constatação de duas lacunas persistentes nas investigações historiográficas: a) a primeira se refere a uma significativa ausência de estudos sistemáticos sobre as relações teóricas, metodológicas e epistemológicas entre instituições jurídico-políticas e os Estudos de Gênero no campo da História; b) a segunda lacuna tem um teor semelhante e complementar, uma vez que, em se tratando dos estudos acerca das instituições políticas castelhano-leonesas do século XIII, especialmente no Brasil, não há trabalhos que tenham se dedicado a pensar criticamente as (des)conexões entre os Estudos de Gênero, a História do Direito Medieval e os discursos jurídicos produzidos no governo afonsino.

Em outras palavras, essa pesquisa adveio de uma insatisfação com a falta de trabalhos que se preocupassem com as (des)conexões entre o Gênero e o Direito (Mohammad FABEL,

${ }^{1}$ Sobre as transversalidades e mobilidades de gênero, verificar, respectivamente, os artigos de Lia Zanotta Machado (1998, p. 108) e Rita SEGATO (1997, p. 235-262).

2 Revista Estudos Feministas, Florianópolis, 26(3): e45295 
1997, p. 185-204). Por exemplo, as diversas correntes jusnaturalistas ou do direito natural, os positivismos jurídicos, as doutrinas ou interpretações socialista-marxistas, pelo menos as estereotipadas pelos manuais de Direito, bem como as concepções mais sociológicas do Direito (jurisprudência de interesse, a Escola do Direito Livre, a jurisprudência sociológica ou o sociologismo jurídico, e o realismo jurídico) pouco prestaram atenção às simetrias, assimetrias, horizontalidades e hierarquias de gênero (Reinaldo DIAS, 2009, p. 100-121; Felippe Augusto de Miranda ROSA, 2001, p. 37-92; Renato TREVES, 2004, p. 3-70; José Manuel de Sacadura ROCHA, 2005; Antonio Sergio SPAGNOL, 2013, p. 15-44; Karl LARENZ, 1997, p. 9-112).

Até certo ponto, isso também se aplica às investigações do Direito Medieval castelhano-leonês (Marcelo Pereira LIMA, 2010b). Como tem assinalado Diana ARAUZ MERCADO (2007) no livro La protección jurídica de la mujer en Castilla y León, há uma significativa ausência de estudos sistemáticos sobre a condição jurídica das mulheres medievais, em geral, e as castelhano-leonesas, em particular. Essa autora sugere que é necessário problematizar os diversos anacronismos existentes nos estudos contemporâneos que procuram acomodar as mulheres do medievo dentro de contextos histórico-jurídicos alheios ao medieval, o que significa dizer que é premente questionar também as generalizações infrutuosas e insensíveis a uma visão de conjunto sobre as mulheres medievais e o gênero (ARAUZ MERCADO, 2007, p. 13-37).

Levando-se em conta uma ótica mais epistemológica, isso tem a ver com a maneira como o campo científico tem formulado os seus "centros" e "margens". No artigo, também inspirado na minha tese, intitulado "Ciência Política, Medievalismo e Estudos de Gênero: a propósito das relações de poder no reino castelhano-leonês, séc. XIII" (LIMA, 2010a), já havia sinalizado que o campo científico poderia vir a possuir uma forte inclinação androcêntrica, bipolar e dual ao propor um conjunto de atributos específicos: a chamada "boa ciência", implícita ou explicitamente, fora considerada forte, rigorosa, racional, impessoal, competitiva, não empática, portanto, frequentemente associada à órbita masculina. Baseando-me na perspectiva da autora americana Sandra HARDING (1986), apontei que as reações contra a "feminização" da cultura poderiam alcançar a esfera da ciência. Sugeri que as configurações e ordenamentos sociais fundamentados no gênero poderiam construir, legitimar, manter e alterar as divisões de trabalho, as práticas e discursos sociais e políticos, mas também os saberes científicos (HARDING, 1986, p. 64, p. 58-81). Neste caso, o gênero da ciência possuiria sua quota de participação na "escolha" de temáticas, problemas científicos, conceitos, teorias, métodos e interpretações de pesquisa (HARDING, 1986, p. 82). Em grande medida, é plausível que as escolhas na medievalística não tenham ainda levado a sério o questionamento das dicotomias formalistas e empiricistas do campo jurídico, bem como a preocupação com as complexas e heterogêneas (des)conexões históricas entre Gênero e Direito na península lbérica na Idade Média.

Por isso, com o objetivo de (re)pensar essa "boa ciência" androcêntrica, proponho a combinação entre uma espécie de Epistemologia Relacional do Direito e uma História Institucional de Gênero, isto é, uma (dis)junção entre uma História Cultural e Institucional do Direito e os Estudos de Gênero. Talvez, como proposta teórico-metodológica, a saída seja evitar a autoevidência das dicotomias sociológico-jurídica versus formalismo jurídico, procurando historicizá-las de modo a investigar criticamente o alcance de suas implicações com o Gênero. Por isso, gostaria de romper o quanto for possível não só com um rígido "sociologismo" jurídico (visão "externalista" do direito, relações mecânicas entre proposições jurídicas e fatos empíricos, direito como puro instrumento do poder etc.), como também com o "formalismo" jurídico (visão "internalista", cuja ênfase está na autonomia lógico-formal das proposições jurídicas, teoria do direito livre ou do "direito pelo direito" (a lei pela lei), teoria psicológica do direito, direito como decisão individual, fenomenologia rígida do 
direito etc.). Se e somente se essa postura for a mais acertada, situar-se-á a minha perspectiva em algum lugar longe do julgamento da esfera jurídica como um objeto autônomo, apelando para a independência da sua organização e lógica internas. Consequentemente, ela estaria longe de forçar a nos mover no sentido de adotar os pressupostos que veem a dimensão jurídica como objeto não suficiente em si mesmo, sendo resultado das funções unilateralmente externas.

Diante desse dilema, cada vez mais, estou inclinado em adotar aqui uma espécie de Epistemologia Relacional do Direito, ou seja, entendo esta como uma esfera complexa, num só tempo, discursiva e prática, definível tão somente de forma historicamente contextualizada, mas estritamente articulável com o que venho chamando de História Institucional de Gênero (HIG). Por HIG entendo as múltiplas, heterogêneas e complexas maneiras como a d(en)ominação institucional (isto é, as relações de poder e os processos de significação) é constituída pelas e/ou constituem as diretrizes de gênero. Em se tratando das instituições monárquicas castelhano-leonesas de meados do séculos XIII, a HIG tem como prioridade o estudo das maneiras pelas quais as instituições sociopolíticas "genderizam" a d(en)ominação assumida por ou atribuída a pessoas, grupos ou outras instituições, (des)articulando-as móvel, transversal e eventualmente aos diversos aspectos prático-discursivos, socioeconômicos, demográficos, culturais, éticos, étnicos, morais, religiosos etc. Essa proposta tem a vantagem de enfatizar as relações entre Gênero e Direito sem domesticá-las do ponto de vista propriamente histórico e historiográfico. Apesar das controvérsias sobre como atua o gênero nas esferas das identidades, dos símbolos, das normas e da organização social, são as experiências discursivas sobre as instituições jurídicas que nos interessam aqui. Situarei esse trabalho, portanto, em algum locus entre os (des)encontros das experiências dinâmicas de se produzir conhecimentos historiográficos e críticos, e as práticas e saberes histórico-jurídicos. São experiências, práticas e saberes localizados na tessitura das temporalidades.

É com esse universo teórico-epistemológico em mente que gostaria de discutir neste artigo se, como e por que as diretrizes de gênero afetam ou são afetadas pela elaboração de leis afonsinas sobre os "boceros", os "personeros" e, de forma mais concentrada, as "testemunhas" presentes no Fuero Real, no Especulo e nas Siete Partidas. A historiografia tem discutido largamente sobre os processos de fabricação dessas três compilações a partir de distintas interpretações. ${ }^{2}$ No entanto, há um relativo consenso na medievística contemporânea de que foi no período de governo de Afonso X (1252-1284) que se alteraram marcadamente as maneiras de elaboração dos discursos e práticas jurídicas iberomedievais. Fortemente marcada pela relativa continuidade de concepções e práticas precedentes, a legislação afonsina foi parte de uma dinâmica de (re)invenção de tradições que não prescindiu da convergência, contradição e pluralidade de discursos jurídicos e não jurídicos. A busca por unidade jurídica e a renovação do direito não excluíam em absoluto a pluralidade de fueros, tampouco estavam separadas do horizonte institucional da corte monárquica castelhana do período. Se, por um lado, parcela do governo afonsino esforçava-se por excluir e restringir determinadas experiências jurídicas locais e regionais, por outro, visava também a englobá-las, reconduzi-las, controlá-las e ressignificá-las. Por

${ }^{2}$ Sobre esse tema, recomenda-se a leitura de trabalhos clássicos, como os textos de Kenneth H. VANDERFORD (1945) e Alfonso GARCÍA-GALLO DE DIEGO (1951-1952; 1976; 1984), passando por revisões importantes, como as de Aquilino IGLESIAS FERREIRÓS (1980; 1982), Gonzalo MARTíNEZ DÍEZ (1980; 1988), Joseph F. O'CALLAGHAN (1999) e Robert A. MACDONALD (1990), até chegar aos artigos recentes de José Sanchez ARCILLA BERNAL (1999), Lima (2015) e María Dolores MADRID CRUZ (2004). Há, ainda, os trabalhos de Juan Antonio ARIAS BONET (1975), José Luis BERMEJO CABRERO (1970), Francisco RAMOS BOSSINI (1984), Jerry R. CRADDOCK (1981a; 1981b; 2001) e José Manuel PÉREZ-PRENDES (1999). 
isso, estou considerando tais compilações como parte de uma comunidade textual e discursiva, já que elas pertenciam a uma mesma unidade processual, compósita, dinâmica, complexa e plural. A ideia é identificar os discursos dos regimes de verdade e formas jurídicas propostas pela legislação afonsina (Michel FOUCAULT, 1979; 1997; 2002a; 2002b), procurando analisá-los a partir da perspectiva de gênero. A hipótese provisória que sugiro aqui é a de que o "direito" das mulheres de falar, representar o outro ou ser representadas em pleitos foi condicionado diversamente pelo gênero, variando em escala desde atitudes permissivas, restritivas ou condicionalmente proibidas.

A primeira questão que se pode destacar é o esforço por parte dos juristas afonsinos em ordenar as atividades propriamente judiciais. Embora não haja processos jurídicos escritos e conhecidos em Castela e Leão do século XIII (algo diferente do que ocorria na França, Itália e Inglaterra), há um intento de ordenar as atividades de um pleito. Só para se ter uma ideia, um dos juristas que procurou fazer isso e que esteve presente na feitura de parte do corpus legislativo afonsino é Jacobo DE LAS LEYES (apud Jean ROUDIL, 1986). Segundo ele:

Todos los pleitos se pueden partir en nueue tiempos el primer tiempo es quando omne faz llamar a otro que le faga derecho el segundo tiempo es quando bienen las partes ante el juez el terçero tiempo es quando alguno llamado diz algunas excepciones o defensiones por que se aluengue el pleito el quarto tiempo es quando se comjença el pleito el quinto tiempo es quando deuen las partes jurar de calunpnja o dezir verdat el sesto es quando las parte o partes aduzen prouas el septimo tiempo es quando las partes rrazonan sobre las prouas o sobre todo el pleito el ochauo tiempo es quando las partes ençierran [e] piden sentencja el nono tiempo es el dar dela sentencja [sic] (p. 143 [grifos meus]).

Desenvolvendo a noção de processo jurídico, Jacobo de las Leyes orienta a maneira ideal de organizar os pleitos, computando nove fases, a saber: a demanda, o comparecimento das partes diante do juiz, as "excepciones" (acusações) ou "defensiones" dilatórias (defesas), a contestação, o juramento de "calunpnja" [sic], a apresentação das provas, a verificação das provas (entendidas especialmente como as palavras ditas por testemunhas), a conclusão do pleito e, por fim, a sentença propriamente dita. Pergunto: será que as diretrizes de gênero interferiam na dinâmica dos processos ou pleitos estilizados pelos juristas afonsinos? A título de exemplificação, concentrar-me-ei no tratamento jurídico dado a algumas "personas" apresentadas nos ordenamentos institucionais da legislação: "boceros", "personeros" e "testigos", justamente aqueles sujeitos que deveriam tomar a palavra para exprimir ou atestar algo ou representar alguém em pleitos judiciais.

Podemos começar com as relações mais explícitas e diretas estabelecidas entre o foro secular e as diretrizes institucionais baseadas no gênero. O primeiro ponto a ser destacado é a contundente exclusão das mulheres em geral no exercício do poder de julgar e a limitação do seu envolvimento nas outras atividades jurídicas. Tudo isso faz parte de um rol de restrições que aparece em algumas seções da documentação. Segundo as Partidas, ao se referir à obrigação de conhecer as leis, "las mugieres se pueden escusar por raçon de fflaca e de liviana natura e aun porque les nos caue de aprender leyes en escuelas nin usar pleytos amenudo entre los uarones" (Primeira Partida, MS. HC 397/573, Título XII, Lei XII, p. 8). ${ }^{3} \mathrm{Na}$ perspectiva da Primeira Partida, da versão novaiorquina, tal como os cavaleiros (devido à sua intrínseca associação com a atividade bélica), os menores de 25 anos (em razão de sua idade) e os camponeses (cujo entendimento recairia tão somente sobre o cuidado da terra),

\footnotetext{
${ }^{3}$ As referências à Primeira Partida, na versão do British Museum, podem ser consultadas na edição crítica organizada por Juan Antonio Arias Bonet. Para simplificar o registro, citamos somente a seção da fonte, seguida do título, lei e página. Cf. Juan Antonio ARIAS BONET (1975).
} 
as mulheres poderiam ser perdoadas por não conhecerem as leis, já que, segundo a mesma documentação, não deveriam aprender conhecimentos jurídicos nas escolas nem participar dos pleitos entre os homens. A justificativa não estava nos limites funcionais e etários, mas em sua "natureza leviana" e na sua "fraqueza" intrínsecas.

Seguindo esta gama de restrições, as mulheres em geral estavam igualmente proibidas de ser "advogados" ou "boceros" (os vocábulos são masculinos!). Para a Terceira Partida, o ofício de advogado era masculino e, longe de ser uma "profissão" especializada no sentido moderno e contemporâneo, constituía uma atividade distinta ou um ofício que possuía determinadas atribuições. O "bocero" era o "ome que razona pleyto de otro en juyzio, o el suyo mismo, en demandando, o en respondiendo" (Terceira Partida, Gregório Lopez, Título VI, Lei I, p. 169). ${ }^{4}$ E teria esse nome "porque con bozes, e con palabras vsa de su officio" (Idem [grifo meu]). Tratava-se de um "sabidor de derecho, o del fuero, o dela costumbre de la tierra" que não apresentasse nenhuma restrição para o exercício do seu ofício. Ou seja, estavam proibidos de ser "bocero" os menores de dez ou sete anos, os surdos, os loucos, os desmemoriados, os que estivessem "en poder ageno" (como os servos, por exemplo), os que não tivessem propriedades, bem como os adúlteros, os traidores, os "de falsedad" (falsificadores), os homicidas etc. A não ser que estivessem exercendo alguma função sob a jurisdição de um mosteiro ou lgreja, os monges e cônegos regulares também não podiam ser advogados (Idem, Título VI, Lei I, II e III, p. 169-171). Em síntese: esse conjunto de restrições seguia critérios muito diversos que se fundamentavam em incapacidades ou limitações mentais, físico-etárias, político-eclesiástico-religiosas, econômicas, morais e jurídicas. O que estava em jogo era uma questão de credibilidade e na capacidade de obter, preservar e comunicar determinados conhecimentos considerados verdadeiros por meio da transmissão oral? Não estou inteiramente certo disso!

Continuando. Nesse rol de proibições, a exclusão das mulheres dessa função seguia uma pauta marcadamente "genderizada". Para a Lei III, Título VI, da Terceira Partida, considerou-se que nenhuma mulher poderia ser "abogado en juyzio", mesmo que fosse "sabidora", por diversas razões. A primeira, porque "non es guisada, nin honesta cosa que la muger tome officio de varon, estando publicamente embuelta con los omes, para razonar por otri" (p. 170-171). A segunda, porque "antiguamente lo defendieron los sabios, por una muger que dezian Calfurnia, que era sabidora: porque era tan desvergonçada, que enojaua a los uezes con sus bozes, que non podian con ella" (p. 170-171 [grifos meus]). Por isso, considerando

la primera razon que diximos en esta ley, e otrosi veyendo, que quando las mujeres pierden la verguenca, es fuerte cosa de oyrlas, e de contender con ellas e tomando escarmiento, del mal que sufrieron de las bozes de Calfurnia, defendieron que ninguna muger non pudiesse razonar por otri (p. 170-171 [grifo meu]).

Segundo o Diccionario Medieval Español, organizado por Martin ALONSO (1986), verbo "razonar" poderia significar: a) "discurrir manifestando lo que se discurre o hablar dando razones para probar una cosa"; b) "Hablar de cualquier modo que sea" (p. 1544). Assim, "razonar por otri" seria tomar a palavra em nome de outra pessoa, estando no seu lugar, substituindo-a, tomando sua palavra, representando seus interesses, tornando-se, por assim dizer, outro sujeito sem deixar de ser o mesmo para atestar algo.

Essa lei reproduz os discursos tradicionais sobre a suposta tagarelice atribuída ao feminino, incorporando-os para legitimar as restrições do ofício de "bocero" às mulheres. Ao

\footnotetext{
${ }^{4}$ As referências à Terceira Partida foram extraídas da versão de Gregório Lopez. Para simplificar o registro, citamos somente a seção da fonte, seguida do título, lei e página. Ignacio SANPONTS Y BARBA; Don Ramon MARTI DE ÉIXALA; Don José FERRER Y SUBIRANA (1844).
}

6 Revista Estudos Feministas, Florianópolis, 26(3): e45295 
fazer referência "historiográfica" à Calpurnia Pisonis, nobre romana e terceira esposa de Júlio Cesar, a lei do século XIII procura justificar a anulação de quaisquer dúvidas sobre os casos em que as figuras femininas fossem consideradas capazes de exercer a representação do outro. $O$ argumento baseava-se em preceitos morais que impediriam o intercurso feminino nas atividades consideradas masculinas do foro secular. Estava vinculado também, contudo, às supostas dificuldades de controle do comportamento feminino, cuja natureza considerada desavergonhada e descontrolada seria preciso conter por meio da exclusão do ofício de "razonar por otri". Ou seja, as mulheres não poderiam ou deveriam discutir ou falar publicamente em lugar de outra pessoa. Embora a lei seja explícita quanto à limitação do feminino na representação do outro em pleitos, não é clara para as concessões de autorrepresentação. Ela apenas aponta que "como quier que ninguno destos non puede abogar por otri, bien lo podria fazer por si mismo, si quisiesse, demandando, o defendiendo su derecho" (p. 171). Se for considerada a expressão "ninguno destos" como sendo uma categoria excludente de todas as figuras proibidas de exercer o ofício de "bocero" de outra pessoa, podemos conjecturar que essa lei era em parte condescendente com a possibilidade de autorrepresentação das mulheres. Mas ela é pouco clara (p. 170).

Mesmo que tenha existido o reconhecimento do saber jurídico como uma capacidade feminina, afinal, seguindo o exemplo-modelo-histórico-negativo de Calpurnia como "sabidora", a lei não considerou isso suficiente para que elas usurpassem oficialmente atividades consideradas masculinas. Ao menos em parte; já que havia outros critérios de exclusão ou restrição a grupos masculinos no exercício do ofício de "bocero", não nos parece que a legislação se baseou na crença de uma intrínseca incapacidade das mulheres de obter, preservar ou comunicar a verdade nos pleitos. Não estava em jogo uma espécie de teoria da verdade jurídica. A questão não estava na incapacidade feminina de distinguir a verdade da falsidade, e representar oralmente o outro em pleitos, pois elas foram consideradas "sabidoras", eventual e potencialmente conhecedoras dos preceitos jurídicos. Pelo contrário, a questão parece girar muito mais em torno da preocupação com as circunstâncias da moralidade e da desmedida atribuída às vozes femininas nos pleitos jurídicos do que sua intrínseca (in)capacidade de comunicação da verdade. Em termos de adesão ao saber jurídico, há relativa simetria e horizontalidade entre o masculino e o feminino. No entanto, para além da associação limitada a esse saber, quando se considera o contato interpessoal e a concepção de sujeito moral desmedido, existiria acentuada assimetria e hierarquias entre homens e mulheres.

De maneira complementar à questão do exercício de "bocero", as Partidas confirmam a atribuição de uma outra relativa incapacidade das mulheres de representar outra pessoa em juízo como "personero", uma espécie de "procurador" na linguagem jurídica e castelhana do século XIII (ALONSO, 1986, p. 1493). Por exemplo, a Terceira Partida estabelece restrições que recaíam sobre numerosos sujeitos sociais: os menores de vinte e cinco anos, os mudos, os surdos e os desmemoriados, os servos (exceto os servos do rei), os monges (a não ser que seja "personero" da sua ordem com a autorização de seu "mayoral", isto é, do abade) e o clérigo ordenado que fosse "de epístola", um subdiácono (exceto em pleitos que envolvem a lgreja, o Prelado ou o Rei) (Terceira Partida, Gregório Lopez, Título V, Lei V, p. 145-146). Ao lado dessas pessoas, proíbe-se que as mulheres em geral se tornem "personeros", excetuando os casos em que estivessem envolvidas em pleitos os "sus parientes que sube, o decienden por la liña derecha, que fuessen viejos, o enfermos, o embargados mucho en otra manera. E esto, quando no ouiesse otri, en quien se pudiessen fiar, que razonasse por ellos" (p. 145). Ou melhor, elas só poderiam assumir a papel de "personeros" nos casos de parentes homens considerados inábeis ou somente como uma segunda opção. Neste caso, ante a inexistência de uma figura masculina confiável, as mulheres só poderiam representar um parente colateral, idoso, 
enfermo ou com outra limitação circunstancial. A ałuação das mulheres em geral deveria ser excepcional ou secundária, embora não excluídas em termos absolutos. Para que "razonasse por ellos", para que tomasse a palavra em seu nome, em seu lugar, a "mulher" deveria fazêlo com raridade ou pouca profusão.

Outras leis foram ainda mais contundentes na imposição de proibições e restrições à representação e autorrepresentação das mulheres em pleitos. A Lei III, Título VII, da Terceira Partida, também prescreve que as mulheres casadas, viúvas, jovens virgens ("donzellas") e outras mulheres, que viviam "onestamente en su casa", não deveriam ser chamadas nos "emplazamientos", isto é, nos tribunais ou pleitos. Era recomendado que elas não se dirigissem ao tribunal pessoalmente para os casos de "justicia de sangre o de otro escarmiento" (castigo). No entanto, há a possibilidade de enviarem um representante homem "en juysio en los otros pleytos". A justificativa é tradicional, já que retoma os argumentos misóginos da proibição da presença feminina no ambiente não doméstico. Em uma clara intertextualidade, a lei demonstra que não seria uma coisa útil ou conveniente ("guisada cosa") que elas estivessem em contato direto e manifesto com os homens. Diz a documentação: "Porque non seria guisada cosa, que tales personas como estas pareciesen embueltas publicamente con los omes, assi como de suso diximos, en el Título que fabla de los abogados" (Terceira Partida, Título VII, Lei III, p. 187-189 [grifo meu]).

Havia outras restrições às mulheres e ao feminino no que concerne à questão das testemunhas. Pelo menos para os textos normativos afonsinos, a capacidade de testemunhar em pleitos era vista como uma atividade basicamente masculina, embora entremeada por restrições socioeconômicas, políticas, religioso-eclesiásticas, morais, étnicas, éticas, parentais, mentais, físicas, etárias etc. Segundo o Especulo, só para citar mais um exemplo, todo "ome puede seer testigo", sobretudo, nos casos em que estava em jogo a segurança do rei e do reino (Especulo, Libro IV, Título VII, Lei I, p. 191). ${ }^{5}$ Estavam proibidos, também, todos aqueles homens que tivessem alguma restrição a essa capacidade, tais como os inimigos dos pleiteantes, os menores de quinze anos, ${ }^{6}$ os "de otra ley" ou de outras crenças (mouros, judeus e hereges), os que tinham "perdido el seso" (loucos), os que possuíam "mala vida" (ladrões, "alcahuetes"), os que disseram falso testemunho, os perjuros, os que não cumpriam a homenagem ao seu senhor, os adivinhos, os feiticeiros e os que desenterravam os mortos (Especulo, Libro IV, Título VII, Lei VI, p. 194-195). Aqueles que ministravam ervas e poções para matar homens e os(as) filhos(as) de mulheres grávidas, os casados que também tivessem "barraganas" (concubinas legítimas), os homicidas, os "que fuerzan las mugeres" (violadores), os que saíssem ou fossem tirados do mosteiro "sin licencia de su mayoral", os que casam com suas "parientas fasta el quarto grado" (incestuosos) e os "alevosos" (traidores). Todos esses sujeitos eram igualmente proibidos de testemunhar e, salvo a concessão real, nunca teriam "onra de poder testiguar como otros omes" (Especulo, Libro IV, Título VII, Lei VII, p. 195196). Além disso, estavam também proibidas de testemunhar as pessoas pobres que possuíssem menos de vinte "maravedíes" em bens móveis e de raiz, bem como os "alcalles" (alcaides) e aqueles que tivessem o "poder de judgar" (Especulo, Libro IV, Título VII, Lei VIII e Lei XXVII, p. 196 e 208). Neste último caso, as autoridades jurídicas não poderiam ser testemunhas do mesmo pleito que estavam sob sua jurisdição. A proibição de testemunhar segue critérios muito diversos, levando em conta uma concepção de ordem hierárquica

\footnotetext{
${ }^{5}$ Para as referências ao Especulo, usamos a seguinte edição, registrando o nome da compilação, livro, título, lei e página: ESPECULO (1836).

${ }^{\circ} \mathrm{A}$ legislação apresenta uma exceção para as pessoas com vinte anos para casos específicos. "Pero dezimos, que en pleito de justicia de muerte, o de lision, o de desterramiento, o por que podiese alguno perder quanto que oviese, non deve niguno seer tertigo a menos de aver edat de veynte años" (Especulo, Libro IV, Título VII, Lei IV, p. 193-194).
}

8 Revista Estudos Feministas, Florianópolis, 26(3): e45295 
bastante complexa, porém uma questão de fundo se coloca: em última instância, não se pode perder de vista que é a autoridade do rei que compensaria eventualmente as (in)capacidades sociojurídicas aventadas pela legislação. É como se a autoridade monárquica tivesse a atribuição, por vezes, de neutralizar/anular/relativizar o conjunto dessas restrições, ausências e incapacidades jurídicas dessas "personas".

Mas onde estão as diretrizes de gênero nesse conjunto de proibições? Há um gênero das e nas testemunhas? As mulheres em geral estavam proibidas de testemunhar em quaisquer situações consideradas graves, como os pleitos de morte, lesão corporal em homens e mulheres, expropriações de bens e desterro. Segundo a legislação afonsina, elas poderiam testemunhar nos pleitos de testamentos, mas, em caráter de exceção, só deveriam fazê-lo naqueles lugares em que não havia homens para ocupar essa posição. Talvez, um dos exemplos de como essa exceção poderia ser aplicada é o caso da feitura do Testamento de Afonso X, outorgado em Sevilha, em 1283, e escrito pelo notário Juan Andres. Ele inclui o nome de $D^{a}$ Beatriz, filha do rei com Mayor Guillén, e casada com Afonso III, de Portugal, como testemunha entre várias autoridades eclesiásticas e seculares (Testamento del Rey D. Alonso X, 1851, p. 121). ${ }^{7}$ A lei ainda aponta que essas mulheres deveriam ter uma característica moral determinada, isto é, ser de "buena fama", ou não possuir quaisquer impedimentos amplos para serem testemunhas (Especulo, Libro IV, Título VII, Lei III, p. 193). Ultrapassando o corte descritivo-sociológico homem-mulher, foram incluídos no rol de proibições para testemunhar os homens andrógenos e travestidos. Para a documentação, perde-se a capacidade de exercer a atividade de testemunha o "ome que aya natura de varon e de mugier, o que ande en semeianza de mugier" (Especulo, Libro IV, Título VII, Lei VI, p. 194, Terceira Partida, Gregório Lopez, Título XVI, Lei XV, p. 313). Não há menções às mulheres andrógenas ou masculinizadas.

A valorização indiciária das testemunhas já era uma tradição romano-canônica bem consagrada. O conteúdo de diversas decretais papais e textos conciliares foi incorporado pelos juristas afonsinos para circunscrever a utilização dos testemunhos de familiares ou membros da comunidade cristã. Na perspectiva da legislação afonsina, o foro eclesiástico privilegiava as testemunhas de familiares do esposo e da esposa quando a questão girava em torno dos interesses para desfazer o casamento por razões de parentesco até o quarto grau, numa evidente apropriação de parcela do discurso sintetizado pelo IV Concílio de Latrão de 1215 (Cânone 50, in Raimunda FOREVILLE, 1972, p. 191-192). O argumento seria de que os parentes dos dois lados estariam mais bem informados sobre os laços consanguíneos e afins, "porque mejor saben ellos el parentesco, que otros ningunos; e se trabajan, quanto pueden, para saber su linaje" (Quarta Partida, Gregório Lopez, Título IX, Lei XV, p. 988-989). Há uma referência geral para os parentes bilaterais, mas a lei define assim as testemunhas: "Testimoniar puede todo ome, que sea de buena fama, sobre pleyto de acusacion, que sea fecha para departir elcasamiento por razon de parentesco o de cuñadez, fasta el quarto grado" (Quarta Partida, Título IX, Lei XV, p. 983-984). Apesar da prioridade testemunhal dos parentes, a legislação aceita a possibilidade de "estraños" exercerem tal papel nas situações ligadas aos casamentos que foram contraídos com alguma irregularidade, como os matrimônios clandestinos, que precisavam ser confirmados externamente. Nos casos de mulheres que negassem ter feito "pleyto de casar" com homens que afirmassem o contrário, as testemunhas poderiam ser os parentes bilaterais, só os dela ou "otros qualesquier de buena fama" (Quarta Partida, Gregório Lopez, Título IX, Lei XVI, p. 984; Quarta Partida, Gregório Lopez, Título IX, Lei XVII, p. 986-985).

${ }^{7}$ Cf. ALFONSO X (1851). 
Como se viu antes, as mulheres, os homens travestidos ou feminilizados foram considerados incapazes de testemunhar na maioria dos pleitos. Em se tratando de casamento, porém, se abria algumas exceções. Uma delas corresponderia aos casos em que essas mulheres fossem parte de grupos aristocráticos hierarquicamente considerados mais ricos, honrados, poderosos e nobres do que os grupos aos quais pertencessem os homens. Neste caso, os testemunhos dos parentes do marido não seriam admitidos em virtude dos seus comprometimentos parentais e dos interesses em prol da ascensão social viabilizada pelo casamento. Esses parentes só seriam admitidos se e somente se as mulheres e os homens pertencessem ao mesmo grupo social, isto é, fossem "eguales" em nobreza, demonstrando que o universalismo das assimetrias e hierarquias entre homens e mulheres poderia ser matizado juridicamente pelos privilégios socioestamentais:

Pero si aquel que demandasse la muger por esposa, non fuesse tan rico, nin tan honrrado, nin tan poderoso, nin de tan buen linage, como ella, non puede aduzir sus parientes en testimonio: porque sospecharian contra ellos, que querian acrescer honrra e pro de su pariente. Mas si fueren eguales en estas cosas sobredichas, bien puede aduzir, aquel que la demanda por esposa, en testimonio sus parientes con los della, o con otros estraños. E si alguna muger demandasse por esposo algund ome, e lo el negasse, en essa misma manera podria testimoniar contra el. (Quarta Partida, Gregório Lopez, Título IX, Lei XVI, p. 984 [grifos meus]).

Há alguns outros exemplos que se referem ainda aos pleitos jurídicos sobre as relações conjugais e a questão do direito das testemunhas. Entre outros aspectos, os testemunhos orais foram considerados as provas mais reivindicadas pelo discurso jurídico afonsino em matéria de pleitos de casamento. Eles deveriam ser aduzidos às presenças dos juízes nos casos de anulação de acordos de "despojas" (esponsais) e de casamentos considerados irregulares em razão de parentesco (incesto). Nestas duas questões, dependendo das circunstâncias, os pais, as mães, os parentes próximos, a comunidade cristã, quer fossem "estraños" ao parentesco dos implicados, quer fossem membros da vizinhança local, a "vezindad", poderiam ser chamados para dizer algo e comprovar situações duvidosas. A legislação previa uma série de proibições e/ou restrições aos testemunhos "de ouvir falar", aos inimigos dos acusados, às pessoas de "mala fama", aos testemunhos interessados em obter vantagens com os pleitos, aos testemunhos motivados por razões alheias à obtenção da "verdad" etc. Acima de tudo, prescrevia-se que os "testigos" deveriam testemunhar sob juramento:

\begin{abstract}
Tales deuen ser los que testimoniaren para desfazer el matrimonio, que fuesse fecho entre algunos, por razon de qual embargo quier, que sea sin pecado mortal, sin otra sospecha mala. E ante que digan el testimonio, deuelos fazer jurar el Juez sobre los Santos Euangelios, o en sus manos, si fuere Obispo o Clerigo Missacantano, en esta guisa: Vos juraes a Dios, e a Santa Maria, e a mi, sobre estos Santos Euangelios, que sobre el parentesco, o otro embargo, que dizen que es entre tal ome, e tal muger (nombrando cada vno dellos por su nome) sobre qual embargo quiere departir el matrinonio que es entre ellos, que vos digaes verdad de lo que sabeys, quier por vista, quier por oyda de vuestros Mayorales, o de otros: e que por amor nin por desamor, nin por don que aues rescibido, nin atendes de rescibir, nin por miedo, nin por otra cosa que ser pueda, que non digaes si non verdad: e aquello que dixieredes en esta razon deste testimonio, que crees que es assi? E ellos deuen responder, que assi lo juran: e el Juez deue dezir, que si lo fizieren assi, que los ayude Dios; e si non, que el los confunda: e deuen responder, amen (Quarta Partida, Gregório Lopez, Título IX, Lei XIX, p. 986-987 [grifo meu]).
\end{abstract}

A lei não deixa claro se o juramento feito sobre a Bíblia, de uma forma mais simples, poderia ser feito ante um juiz secular. De qualquer forma, o juramento deveria ser performatizado e oralizado sob o foro eclesiástico, sobretudo ante o bispo e o preste. Não se 
sabe se a expressão "otro embargo" era a forma como os juristas afonsinos entendiam as práticas adulterinas, mas eles proibiam quaisquer testemunhas que tivessem cometido pecado mortal. Como fica evidente no Especulo, desautorizava-se uma pessoa adúltera de participar de quaisquer pleitos. Isso ocorreria em virtude da tendência para se fazer corresponder o que uma pessoa diz sobre si, e sobre os outros, com quem ela era ou deveria ser em termos sociais e morais. Em outras palavras, o que se dizia como "testigo" deveria ser diretamente proporcional a quem se era.

Havia amplas restrições jurídicas às prerrogativas para o acesso feminino à condição de testemunha, mas, mesmo assim, isso não impediu que alguns tipos de mulheres consideradas moralmente idôneas fossem admitidos para testemunhar em pleitos de casamento, ressaltando fissuras morais no universalismo associado ao feminino. Tratava-se da "buena muger" para os casos de "despojas" não consumadas e contraídas "por palabras del tiempo que es por venir" (per verba de praesente, seguindo a tradição romanocanônica), ou seja, as "mugeres de buena fama" poderiam servir de testemunha ocular em casos de violação e legitimação de filhos (Quarta Partida, Gregório Lopez, Título IX, Lei XVIII, p. 985-986): "E otrosi, si fuesse pleyto en razon de alguna muger, que dizen, que es corrompida, o de muger que dezian que fincaua preñada de su marido: ca tales contiendas como estas se deuen librar por vista de mugeres de buena fama" (Terceira Partida, Gregório Lopez, Título XIV, Lei VIII, p. 278-279 [grifos meus]). Não me parece uma conjectura impossível considerar que os juristas afonsinos tinham em mente a associação do feminino ao conhecimento do plano doméstico e do corpo feminino alheio para servirem como provas. Do ponto de vista jurídico, isso era uma estratégia para alcançar as esferas circunstanciais onde não era conveniente que se adentrasse o poder jurisdicional e masculino.

Extrapolando um pouco as conjecturas aqui aventadas, não seria também algo improvável que este conhecimento, suposta e diretamente inacessível ao juiz, tenha sido cogitado em virtude dos saberes corporais das mulheres sobre o corpo feminino úteis em casos de identificação de lesões e de sinais de gravidez. Ou melhor, não se tratava somente de um tabu do acesso ao corpo feminino que não deveria/poderia ser visto pelo juiz. Ao lado disso, havia o pressuposto da existência de um saber prático, um savoir faire, associado às mulheres sobre outras corporeidades femininas. É interessante comparar essa norma com as prescrições gerais sobre as lesões corporais que gerassem desonra. Estas foram tratadas de uma forma especial, priorizando a avaliação direta do olhar do juiz, sem que as testemunhas fossem descartadas totalmente. Eis o trecho: "E si querellasse alguno antel, que le fiziera otro gran desonrra en su cuerpo, la qual desonrra assi era tan grande, que non se podria aueriguar por testigos tan solamente, a menos de ver el Judgador, qual fue la desonrra, e en qual logar de su cuerpo fue fecha" (Terceira Partida, Título XIV, Lei XIII, p. 289). Provavelmente, esse método indiciário de olhar para medir a gravidade de um dano corporal não foi cogitado para ser aplicado ao corpo feminino em casos de violação ou filiação duvidosas. Definitivamente, o olhar e o ver para falar não eram sempre algo considerado neutro em relação às marcas assimétricas de gênero.

No entanto, quanto aos pleitos acusatórios de adultério, nenhuma personalização universal do feminino foi cogitada. Como demonstra a Lei XII, Título XIV, Terceira Partida, apenas há menções vagas aos "testigos" correspondentes aos interesses do marido em processos de acusação contra a esposa e seu amante. A única menção que se encontrou sobre a relação entre adultério feminino e testemunha só demonstra a situação de impedimento de mulheres adúlteras de servirem de "testigos" para pleitos de testamento, mas não demonstra explicitamente o direito de as mulheres servirem de testemunhas nos pleitos de adultério. Segundo a Lei XV, Título XVI, da Terceira Partida: 
Muger de buena fama puede ser testigo en todo pleyto, fueras ende en testamento. Esso mismo dezimos del que ouiesse natura de varon, e de muger: pero si la natura deste atal tirasse mas a varon que a muger, bien podria ser testigo en todo pleyto de testamento. E esto se entiende, si fuere de buena fama. Mas si contra la muger fuesse dado juyzio de adulterio, o fuesse vil, e de mala fama, non deue ser cabido su testimonio en ningund pleyto, assi como de suso diximos (Terceira Partida, Gregório Lopez, Título XVI, Lei XV, p. 313 [grifos meus]).

Retomando e alterando o conteúdo jurídico já tratado vagamente no Especulo, a Terceira Partida aponta que as mulheres de "boa fama" poderiam ser testemunhas em quaisquer pleitos, com exceção dos pleitos de testamento. Da mesma forma, as pessoas com gênero ambíguo, isto é, aquele(a) que "ouiesse natura de varon, e de muger", também não poderiam servir de testemunha nesses processos. A prescrição não se aplicaria para aquelas pessoas que tivessem um grau ou uma certa escala de masculinidade maior do que sua feminilidade. No caso de pleitos de adultério, as mulheres infamadas ou prostitutas estavam proibidas de participarem de quaisquer contendas jurídicas. Mas as mulheres de boa fama teriam direito de fazê-lo? A lei não é explícita, deixando nas entrelinhas a possibilidade remota de elas participarem dos processos de acusação.

O que explicaria esse silêncio? Apesar das exceções e concessões feitas ao feminino, parece-nos ainda válida a conjectura de que as mulheres foram consideradas em geral um sujeito passivo, não autônomo ou incompleto em termos jurídicos para servirem sistematicamente como testemunhas na maioria dos pleitos. Provavelmente, pelo menos do ponto de vista dos juristas afonsinos, isso valeria também para os processos de acusação de adultério. Ou melhor, levando em consideração as implicações para a honra masculina, vista como vilipendiada pela traição da mulher, é possível dizer que o silêncio também tenha algo a ver com o pressuposto de que as testemunhas eram sujeitos masculinos. Afinal, como dizem as Partidas, "Testimoniar puede todo ome, que sea de buena fama sobre pleyto de acusacion (...)" (Quarta Partida, Gregório Lopez, Título IX, Lei XV, p. 984). Não se sabe se a transitividade da desonra entre homens, transmitida pela mulher adúltera do amante ao esposo, tem algo a ver com a invalidação dos testemunhos em processos acusatórios. É provável que a restrição geral da participação feminina seja a explicação mais consistente dada às evidências documentais (LIMA, 2010, p. 255-272).

Ao analisarmos detidamente as restrições que afetam as mulheres, comparando-as coma as outras limitações ao exercício de capacidades jurídicas associadas às figuras masculinas, percebemos que a questão não é, em termos absolutos, uma proibição exclusiva e universal à "mulher" e seu acesso ao foro jurisdicional secular e ou eclesiástico. Vimos antes que as exclusões à condição de "testigo" passavam por uma série de critérios socioeconômicos, políticos, religiosos, morais, etários, étnicos etc., porém, no que tange às mulheres de má fama, aos homens andrógenos e aos homens travestidos de mulheres, o gênero parece ser um fator marcante como critério de distinção, hierarquização e distribuição de capacidades, de direitos e privilégios. Há alcances jurídicos díspares. Cabe dizer ainda que as diretrizes de gênero não eram algo evidente só porque havia um sistema jurídico marcadamente masculino, patriarcal e androcêntrico. Esse aspecto é o mais óbvio na documentação. Em algumas situações, as questões de gênero afetam o interior de cada categoria relacionada ao universo masculino e feminino. Talvez isso se explique porque o ato de testemunhar foi considerado uma atribuição basicamente masculina. A inclusão dos homens andrógenos e/ou travestidos no rol de proibição justificava-se não somente pela transgressão à sexualidade como também à proximidade desses homens ao feminino associado à lógica da passividade (Ruth Mazo KARRAS, 2005, p. 1-27). Tal como acontece com a sodomia, a androgenia e o travestismo possuíam uma força disruptora e 
desestabilizadora porque eram considerados uma perturbação na ordem social e natural das coisas. Em parte, a ambiguidade ou indeterminação do domínio do masculino, aproximando-o de certa concepção de feminino, desabilitaria o exercício da capacidade de testemunhar, de fazer-se representar e, em última instância, de falar em pleitos. Então, não seria forçoso dizermos que as restrições à capacidade de testemunhar não eram só e simplesmente uma limitação à "mulher", como categoria sociológico-descritiva ou como abstração absoluta. Era também uma restrição ao que representava o feminino ou a feminilidade naquela sociedade, já que até mesmo as mulheres de "má fama" e os homens que tivessem "natura de varon e de mugier, o que ande en semeianza de mugier" não teriam capacidades jurídicas para testemunhar.

\section{Considerações finais}

Segundo Claudia de Lima Costa (1994), a relação entre gênero e linguagem precisa ser pensada a partir de uma proposição de que o gênero é um processo moldado por escolhas individuais, pressões situacionais e contextos de interação social, combinandose de forma não monolítica, mas complexa, múltipla e heterogênea. Seguindo as pautas teóricas dessa autora, pode-se ir além das perspectivas que veem essa categoria de análise como uma variável binária, como sinônimo de papéis sociais rígidos e dicotomizados, como uma variável meramente psicológica ou como sistemas ou subsistemas culturais descontextualizados. Todavia, é profícuo levar em conta as dimensões plurais, complexas, relacionais e transversais das relações de gênero realizadas, irrealizadas ou irrealizáveis. Ou melhor, adaptando para a esfera dos Estudos de Gênero, aqui, faço uma paráfrase ao que fora proposto pelo teórico literário Antônio JARDIM (1997) ao repensar o próprio conceito de realidade de uma maneira bastante ampla e distante das proposições dicotômicas de fundo entre teoria e prática, algo compatível com que foi discutido por Cornelius CASTORIADIS (1995) e Judith BUTLER (1998; 2003). Para Jardim (1997), a realidade se "compõe do realizado, é verdade, mas se compõe também do irrealizado, e muitas vezes, mesmo do irrealizável", ou seja, das diversas formas imaginárias ou não de vigência e performance dos seres humanos no mundo, incluindo as estilizações do uso jurídico da linguagem (JARDIM, 1997, p. 6). Tudo isso significa dizer que não há uma relação natural entre gênero e linguagem, sendo importante identificar e analisar se, como e por que essas configurações históricas interferem variavelmente uma sobre a outra, sem deixar de considerar outros marcadores sociais.

A partir dessa perspectiva, intentamos, neste artigo, mapear e analisar o jogo discursivo de permissões, restrições ou proibições que não pode ser desvinculado do complexo e heterogêneo processo de unificação jurídica e renovação do direito perseguido pelas autoridades monárquicas afonsinas em meados do século XIII. Ao menos as que estiveram envolvidas com a elaboração dos textos e discursos legislativos! As normas que recaíram sobre quem poderia ou deveria ser "bocero", "personero" e, sobretudo, "testigo" (em especial para pleitos de casamento), seguiam critérios diversos, pautando-se em uma dimensão prescritiva e condicional. Tais critérios eram eventualmente permitidos ou neutralizados pela autoridade do rei ou sua legislação. As exclusões, proibições e restrições eram genéricas às mulheres e ao feminino, mas, embora não fossem absolutas, fundamentavam-se em pressupostos naturalizados e essencializações fissuradas em termos jurídico-cristãos.

Seja como for, apesar de não terem sido o único critério de assimetrização e hierarquização sociais, as diretrizes de gênero atuaram com transversalidades e mobilidades muito diversas nos discursos jurídicos afonsinos. Essas operações jurídicas se estenderam 
não somente à mulher e às mulheres, sociologicamente estilizadas na documentação, como também a determinados tipos de feminino ou feminilidade. $O$ intercurso e a convivência morais entre homens e mulheres, a desmedida da oralidade feminina e o grau de feminilidade ou masculinidade parecem ter sido elementos aventados como base para a exclusão ou restrição do feminino no que fora imaginado como exercício de práticas, atividades ou ofícios jurídicos.

Para o ofício de "bocero" e de "personero", a questão esteve mais ligada às restrições da representação e autorrepresentação do feminino por questões morais e de convivência entre homens e mulheres, isto é, haveria uma espécie de "custo" social e moral ditado pelas circunstâncias da organização desses ofícios e atividades jurídicas que excluiriam ou restringiriam a presença feminina. As mulheres deveriam ser excluídas genericamente não porque seriam irracionais ou pouco fiéis à verdade. No caso dos "testigos", a questão não parece girar completamente em torno de uma certa desconfiança da capacidade éticomoral feminina de obter, preservar ou comunicar oralmente a verdade, distinguindo-a da falsidade (sem dúvida, uma incapacidade suposta ou pressuposta aqui e ali de uma forma genérica e, talvez, relativamente independente do gênero). Isso se aplicaria em situações determinadas, mesmo considerando as exceções das "mulheres de boa fama" e as concessões feitas às circunstâncias do testemunho feminino, conveniente para o acesso direto ao corpo das mulheres no plano doméstico.

Podemos aventar a hipótese de que as (in)capacidades atribuídas às mulheres, ao feminino e à feminilidade diziam respeito às concepções de atores sócio-jurídicos "genderizados", naturalizados e estilizados, mas também levavam em conta as circunstâncias do uso das palavras e das ações inconvenientes. Tais circunstâncias morais (in)viabilizavam a exclusão, proibição, restrição ou permissão condicionais para as mulheres representar, se autorrepresentar ou falar como testemunha. Embora o rei ou sua autoridade jurídico-legislativa pudesse compensar, alterar ou anular circunstancialmente determinadas hierarquias e assimetrias entre sujeitos e situações, sem dúvida, o direito de falar dos atores sociais não era avaliado com os mesmos critérios. Nas documentações prescritivas analisadas, o "quem", o "como", o "onde", o "quanto", o "com quem" e o "para quem se dizia algo" em termos jurídicos não era avaliado como um atributo neutro em termos de gênero. Embora não desconectado de outros fatores socioculturais e históricos do direito, da voz e da representação social, o discurso afonsino parece reproduzir um regime de verdade complexo e variável, mas comprometido com as formas jurídicas masculinas e estilizadas pelas instituições monárquicas afonsinas. Seguindo as orientações de Joan W. Scott (1995), é pertinente analisar como as "instituições sociais incorporaram o gênero nos seus pressupostos e nas suas organizações" (p. 50).

\section{Referências}

ALFONSO X. Testamento del Rey D. Alonso X otorgado en Sevilla a 8 de Noviembre de 1283. In: Memorial Historico Español: colección de documentos, opúsculos y antiguedades. Real Academia de la Historia. Madrid: Imprenta de la Real Academia de la Historia, 1851.

ALONSO, Martin. Diccionario Medieval Español: desde las Glosas Emilianenses y Silenses (s. $X)$ hasta el siglo XV. Tomo II. Salamanca: Universidad Pontificia de Salamanca, 1986.

ARAUZ MERCADO, Diana. La protección jurídica de la mujer em castilla y león (siglos XIIXIV). Junta de castilla y león: Consejería de Cultura y Turismo, 2007.

ARCILLA BERNAL, José Sanchez. "La obra legislativa de Alfonso X el Sabio. História de una polémica”. In: MONTOYA MARTÍNEZ, Jesús; DOMÍNGUEZ RODRÍGUEZ, Ana (Coord.). EI 
scriptorium alfonsí: de los Libros de Astrología a las Cantigas de Santa María. Madrid: Editorial Complutense, 1999.

ARIAS BONET, Juan Antonio. Primeira Partida. Manuscrito Add. 20.787 del British Museum. Valladolid: Universidad de Valladolid, 1975.

BERMEJO CABRERO, José Luis. "En torno a la aplicação de Las Partidas. Fragmentos del Especulo en una sentencia real de 1261". Hispania Revista Española de Historia. Madrid, Tomo 30, 1970.

BUTLER, Judith. "Fundamentos contingentes: o feminismo e a questão do pós-estruturalismo". Cadernos Pagu, n. 11, p. 11-42, 1998.

Problemas de gênero: feminismo e subversão da identidade. Rio de Janeiro: Civilização Brasileira, 2003.

CASTORIADIS, Cornelius. A instituição imaginária da sociedade. São Paulo: Paz e Terra, 1995.

COSTA, Claudia de Lima. "O leito de Procusto: gênero, linguagem e as teorias feministas". Cadernos Pagu, v. 2, p. 141-174, 1994.

CRADDOCK, Jerry R. "La cronología de las obras legislativas de Alfonso X el Sabio". Anuario de Historia del Derecho Español, n. 51, p. 366-418, 1981 a.

"La cronología de las obras legislativas de Alfonso X el Sabio". AHDE, n. 51, p. 376386, $1981 \mathrm{~b}$.

"The Partidas: bibliographical notes". In: PARSON SCOTT, Samuel; BURNS, Robert I. Las Siete Partidas. The Medieval Church. The world of Clerics and Laymen. Philadelphia: University of Pennsylvania Press, 2001.

DIAS, Reinaldo. Sociologia do Direito: abordagem do fenômeno jurídico como fato social. São Paulo: Atlas, 2009.

ESPECULO. Opúsculos legales del Rey Don Alfonso El Sabio (publicados y cotejados con varios códices antiguos por la Real Academia de la Historia). Tomo I. Madrid: Imprenta Real, 1836.

FABEL, Mohammad. "Two women, one man: knowledge, power, and gender in medieval sunni legal thought". International Journal of Middle East Studies, n. 29, p. 185-204, 1997.

FOREVILLE, Raimunda. Lateranense IV, v. 2. Vitória: Eset, 1972.

FOUCAULT, Michel. As palavras e as coisas. São Paulo: Martins Fontes, 2002a. A verdade e as formas jurídicas. Rio de Janeiro: Nau Editora, 2002b. Microfísica do poder. Rio de Janeiro: Graal, 1979. Vigiar e punir: nascimento da prisão. Petrópolis: Vozes, 1997.

GARCÍA-GALLO DE DIEGO, Alfonso. "El libro de las leys de Alfonso el Sabio. Del Especulo a las Partidas". AHDE, n. 21-22, p. 345-528, 1951-1952.

"La obra legislativa de Alfonso X. Hechos e hipótesis". AHDE, n. 54, p. 97-161, 1984.

"Nuevas observaciones sobre la obra legislativa de Alfonso X". AHDE, n. 46, p. 509$570,1976$.

HARDING, Sandra. "Androcentrism in biology and social science". In: The science question in feminism. New York: Cornell University Press, 1986. p. 64, 58-81.

IGLESIAS FERREIRÓS, Aquilino. "Alfonso X el Sabio y su obra legislativa: algunas reflexiones". $A H D E$, n. 50, p. 445-465, 1980.

"Alfonso X, su labor legislativa y los historiadores". Historia Instituciones Documentos, n. 9, p. 9-112, 1982.

JARDIM, Antônio. Música: vigência do pensar poético. 1997. Tese (Doutorado) - Faculdade de Letras, UFRJ, Rio de Janeiro. 
KARRAS, Ruth Mazo. "Sex and the middle ages". In: Sexuality in medieval Europe. Doing unto others. New York and London: Routledge, 2005.

LARENZ, Karl. Metodologia da ciência do Direito. Lisboa: Fundação Calouste Gulbernkian, 1997.

LIMA, Marcelo Pereira. "Do pecado ao gênero da confissão religiosa: algumas reflexões sobre a concepção de pessoa na legislação afonsina, século XIII". Revista Signnum, Belo Horizonte, v. 11 , n. 1, 2010a. Disponível em: http://www.abrem.org.br/revistasignum/index.php/ revistasignumn 1 1/article/view/11/10. Acesso em: 30/11/2017.

O gênero do adultério no discurso jurídico do governo de Afonso X. 2010b. Tese (Doutorado) - Instituto de Ciências Humanas e Filosofia, Departamento de História, Universidade Federal Fluminense, Rio de Janeiro. Disponível em: http://www.historia.uff.br/ stricto/td/1260.pdf. Acesso em: 11/2017.

"Comparando a fabricação de códigos afonsinos: o Especulo, o Fuero Real e as Siete Partidas". Revista de História Comparada, UFRJ, v. 9, p. 6-42, 2015.

MACDONALD, Robert A. Especulo. Texto jurídico atribuido al Rey de Castilla Don Alfonso X el Sabio. Madison: Hispanic Seminary of Medieval Studies, 1990.

MACHADO, Lia Zanotta. "Gênero, um novo paradigma?". Cadernos Pagu, n. 11, p. 107-125, 1998.

MADRID CRUZ, María Dolores. "Acerca de la vigencia del Fuero Real: algunas disposiciones procesales del Concejo de Ágreda en 1306". Cuadernos de Historia del Derecho, n. 11 , p. 227-275, 2004.

MARTíNEZ DÍEZ, Gonzalo. Leyes de Alfonso X. Fuero Real. Ávila: Fundación Sánchez-Albornoz, 1988.

"Los comienzos de la recepción del derecho romano en España y el Fuero Real". Diritto Comune e Diritti locali nella Storia dell'Europa, Milán, p. 253-262, 1980.

O'CALLAGHAN, Joseph F. "El rey y sus reinos". In: . El Rey Sabio: el reinado de Alfonso $X$ de Castilla. Sevilla: Secretariado de Publicaciones; Universidad de Sevilla, 1999. p. 25-37.

ORLANDI, Eni P. A linguagem e seu funcionamento: as formas do discurso. Campinas: Pontes, 2003.

Análise de discurso: princípios e procedimentos. São Paulo: Pontes, 2000.

. Discurso \& Leitura. São Paulo: Cortez; Campinas: Editora da Universidade de Campinas, 2001 a.

Discurso e Texto. Campinas: Pontes, $2001 \mathrm{~b}$.

PÉREZ-PRENDES, José Manuel. "Las leyes de Alfonso X el Sabio, Interpretatio". Revista de Historia del Derecho, Granada, n. 8, v. 1, 1999.

RAMOS BOSSINI, Francisco. Primeira Partida (MS.HC.397/573). Hispanic Society of América. Granada: Caja General de Ahorros y Monte de Piedad de Granada, 1984.

ROCHA, José Manuel de Sacadura. Fundamentos e fronteiras da sociologia jurídica los clássicos). São Paulo: Juarez de Oliveira, 2005.

ROSA, Felippe Augusto de Miranda. Sociologia do Direito: o fenômeno jurídico como fato social. Rio de Janeiro: Zahar, 2001. p. 37-92.

ROUDIL, Jean (Ed.). Summa de los Neuve Tiempos de los Pleitos. Paris: Klincksieck, 1986.

SANPONTS Y BARBA, Ignacio; MARTI DE ÉIXALA, Don Ramon; FERRER Y SUBIRANA, Don José (Ed.). Las Siete Partidas del Sabio Rey D. Alonso el IX, con las variantes de mas interés, y con la glosa de Lic. Gregorio Lopez del Consejo Real de Indias de S. M. Barcelona: Imprenta de Antonio Dergnes, Tomo IV, 1844.

SCOTT, Joan Wallach. "Gênero: uma categoria útil de análise histórica". Educação \& Realidade, Porto Alegre, v. 20, n. 2, p. 71-99, jul./dez. 1995.

16 Revista Estudos Feministas, Florianópolis, 26(3): e45295 
SEGATO, Rita L. "Os percursos do gênero na Antropologia e para além dela". Sociedade e Estado, Brasília, v. 121, n. 2, p. 235-262, 1997. (Volume dedicado a Feminismos e Gênero) SPAGNOL, Antonio Sergio. Sociologia Jurídica. São Paulo: Saraiva, 2013.

TILLY, Louise A. "Gênero, História das Mulheres e História Social". Cadernos Pagu, Campinas, UNICAMP, n. 3, p. 29-62, 1994.

TREVES, Renato. Sociologia do Direito: origens, pesquisas e problemas. São Paulo: Manole, 2004.

VANDERFORD, Kenneth H. Setenario. Buenos Aires: Facultad de Filosofía y Letras de la Universidad de Buenos Aires, 1945.

VARIKAS, Eleni. "Gênero, experiência e subjetividade: a propósito do desacordo Tilly-Scott". Cadernos Pagu, Campinas, n. 3, p. 63-84, 1994.

[Recebido em 24/06/2016, reapresentado em $02 / 12 / 2017$

e aprovado em $27 / 02 / 2018$ ]

The "Right" to Speak in Lawsuits: the Gender in the Legal Codes of the Government of Afonso $X$

Abstract: This article is not an attempt to study the vocality and orality in written and legal texts. What I have in mind is whether, how and why gender guidelines acted in cross ways in the speeches made by government legislation of Alfonso X (1252-1284), especially with regard to certain activities, practices or legal offices which are directly or indirectly associated with the credibility of the talk or the use of words. The proposal here is to test the limits and possibilities of proposing an Institutional History of Gender, combining the field of Cultural History of Medieval Law and Gender Studies. Discusses the intersectionality between power relations and processes of meaning, ie, "d(en)omination". Keywords: Gender; Language; Alfonso X; History of the Medieval Law

Marcelo Pereira Lima (inperpetuum@uol.com.br) é graduado e licenciado em História pela Universidade Federal do Rio de Janeiro (1997). Nesta universidade, tornou-se também mestre em História Social pelo PPGHIS (2001). É doutor em História pelo PPGH da Universidade Federal Fluminense (2010) e pós-doutor pela Universidade de Salamanca (2015), com bolsa concedida pela Coordenação de Aperfeiçoamento de Pessoal de Nível Superior (CAPES). Atualmente, faz parte de diversos grupos e laboratórios de pesquisa no Brasil, tais como o Cultura Material, Antiguidade e Cotidiano (Colíder-CMAC/UFBA), o Poder, Política e Instituições Eclesiásticas no Ocidente (séculos XI a XVI) - UFMT (pesquisador); o Programa de Estudos Medievais - UFRJ (pesquisador); o Translatio Studii, Núcleo Dimensões do Medievo História, Língua e Filosofia - UFF (pesquisador). Juntamente com o Prof. Dr. Marco Aurélio Oliveira da Silva (PPGF-UFBA), coordena o Laboratório de Estudos sobre a Transmissão e História Textual na Antiguidade e Medievo (LETHAM-UFBA). É editor-gerente e membro do Conselho Editorial da Revista Veredas da História - UFRRJ/UFPel/UFBA/UFMT/UFS (presidente). É também membro do Conselho Editorial da Revista Medievalis (NIELIM-UFRJ) e da Revista Gênero \& Direito (G\&DUFPB). Faz parte do Conselho Consultivo da ABREM (Associação Brasileira de Estudos Medievais). Tem experiência na área de História, com ênfase na História Sociocultural das Instituições Medievais, sobretudo na História da Igreja e do Papado, da Realeza Medieval e da História do Direito Medieval. Além disso, dedica-se à pesquisa sobre os Estudos de Gênero e seus fundamentos teóricos, metodológicos e epistemológicos, investigando, portanto, os seguintes temas: Teoria e Metodologia da História, Idade Média, Direito Medieval, Reforma Papal, Realeza Castelhano-Leonesa, Relações de Poder, Corpo, Parentesco e Gênero.

0000-0001-9836-3149 